\title{
Design of Axial-Flux Motor for Traction Application
}

\author{
Nadia Chaker, Ibrahim Ben Salah, Souhir Tounsi, Rafik Neji
}

Ecole Nationale d'Ingénieurs de Sfax (ENIS), BP. 1173, 3038 Sfax Tunisie, Laboratoire d'Electronique et des Technologies de l'Information (LETI), Equipe Véhicule Electrique et Electronique de Puissance (VEEP), Tunisia.

Email: nadia.chaker@enis.rnu.tn,rafik.neji@enis.rnu.tn

Received February $9^{\text {th }}, 2009$; revised March $26^{\text {th }}, 2009$; accepted April $2^{\text {nd }}, 2009$.

\begin{abstract}
This paper deals with the design of high power - low dimensions axial-flux permanent-magnet motor intended for traction application. First, two motor configurations are analytically designed and compared using finite element calculation. Then, the configuration yielding the best performances is integrated and modelled with the whole traction chain under MATLAB/SIMULINK environment in order to demonstrate the motor operation on a large speed band.
\end{abstract}

Keywords: Axial-Flux Permanent-Magnet Motor, Design Criteria, Finite Elements, Traction Chain, Circulation Mission

\section{Introduction}

Nowadays, the use of internal combustion engines in vehicles is one of the principal causes of several pollution problems as air and sound ones. Therefore, the electrical vehicles constitute an excellent candidate to avoid these problems. However, since their appearance, the major problems of this type of vehicles remain in high cost, weak autonomy and over speed problems. For that, it becomes essential to give a particular care when choosing the principal element of the electric traction chain which is the electric motor.

For electric traction applications, synchronous or asynchronous motors [1] with radial or axial fluxes [2,3], can be used. In order to increase the torque generation capability, these motors can be modulated. Moreover, the consequent progress of the permanent-magnet technology makes permanent magnets synchronous motors more and more utilized for variable speed and high performance systems.

In [4], an effectiveness and mass comparison study between radial and axial structures of a permanent-magnet synchronous motor was presented. For a constant power, it was demonstrated that the axial configuration with 4 pole pairs in rotor and 6 teeth in stator has the best compromise effectiveness-mass. Thus, this motor appears particularly interesting for electric vehicle applications. In fact, the axial-flux permanent-magnet motor has many advantages [5] as: 1): high effectiveness and high power factor, 2) high specific power, 3) no ring-brushes and 4) possibility of modularity.

As an industrial application we can mention that JEUMONT industry used the technology of axial flux structures to develop high power machines intended to boats and Aeolian alternators driving [6].

This paper presents the design of a high power - low dimensions axial-flux permanent-magnet motor for a traction application. First, the design criteria of electrical parameters are highlighted for trapezoidal and sinusoidal motor configurations. Then, considering the vehicle specification, the motor geometric parameters are analytically determined for a comparison based on finite element calculation between both configurations performances. Finally, a traction chain integrating best configuration is modelled under MATLAB/SIMULINK environment in order to demonstrate the motor operation on a large speed band without weakening flux method.

\section{Generalities about Axial-Flux Permanent- Magnet Motor}

Several axial-flux machine configurations exist depending on the stator(s) position(s) with respect to the rotor(s) ones, as shown in Figure 1. We can find:

- A structure with one rotor and one stator, Figure 1 (a).

- A structure, in which the rotor is located between the stators, Figure 1(b).

- A structure, in which the stator is located between the rotors, Figure 1(c).

- A multistage structure including several rotors and stators Figure 1(d).

In traction applications, more the motor has higher torque generation capabilities more it is interesting. As 


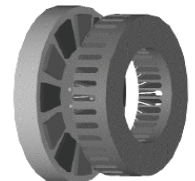

(a)

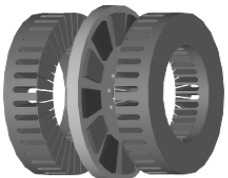

(b)

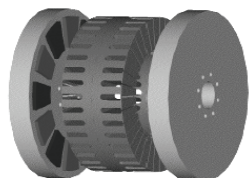

(c)

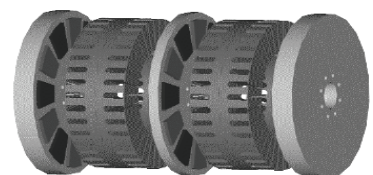

(d)

Figure 1. Permanent-magnet axial-flux machines configurations. Legend: (a): Single-rotor - single-stator structure; (b): Single-rotor - two-stators structure; (c): Two-rotors - single-stator structure, called hereafter also as AFIPM machine (Axial-Flux Interior rotor Permanent-Magnet machine); (d): Multistage structure including two stator blocks and three rotor blocks [2]

radial-flux motors, the axial-flux ones can be modulated which leads to the increase of their torque generation capabilities $[1,2,4]$. In fact, the four configurations shown in Figure 1 are used for traction applications. The torque generated with the fourth configuration, composed of four modules (Figure 1(d)), is twice times greater than the torque of the third and the second configurations which contain two modules, Figure 1(c) and Figure 1(b), and four times than the first configuration developed torque (one module), Figure 1(a).

It is to be signalled that configurations illustrated in Figure 1(b) and Figure 1(c) have the same torque generation capabilities and the choice between both depends if the application needs an outer or inner rotor.

In the present paper, we have been interested in the integration of the axial-flux technology for automotive traction application as shown in Figure 2.

\section{Analytical Design of the Unit Motor - Inverter}

In the present section, the single-rotor - single-stator structure which is the simplest axial-flux permanentmagnet motor configuration [7] is considered, Figure 1(a). At the beginning and in order to satisfy the design criteria

$$
E_{C}=-N_{s p h} d \varphi / d t=-N_{s p h} \Omega_{\max } d \varphi / d \theta \quad \Rightarrow
$$

Taking in account the vehicle specification mentioned in Table 1, the motor must develop a torque of $\mathrm{T}_{\mathrm{em}}=$ $40.625 \mathrm{Nm}$ with a maximum value of back e.m.f equal to $\mathrm{E}_{\mathrm{c}}=138.462 \mathrm{~V}$.

$$
E_{C}=N_{s p h} \Omega_{\text {max }}\left(D_{e x t}^{2}-D_{\text {int }}^{2}\right) B_{e} / 4
$$

of the motor associated to its inverter, the electrical parameters are calculated for two configurations: the three-phase motor with trapezoidal back e.m.f wave form and the three-phase motor with sinusoidal back e.m.f wave form. Then, in order to define the structure of the considered motor configurations, the geometrical parameters are analytically calculated, using the vehicle specifications recapitulated in Table 1 (Appendix).

During the design process it is required that: when the vehicle reaches the maximum specified speed, the motor is controlled with full wave form and develops the needed torque. At this operation point:

- The electromagnetic torque $T_{\mathrm{em}}$, via the mechanical transmission system (reducer and differential), is expressed as the following:

$$
T_{e m}=T_{d m} V_{b} / V_{\max }
$$

where $\mathrm{T}_{\mathrm{dm}}$ is the starting torque expressed as:

$$
T_{d m}=\frac{R_{w}}{r_{d}}\left(\left(\sigma M_{v} V_{b} / t_{d}\right)+M_{v} g \sin (\lambda)\right) .
$$

- The maximum value of the motor back e.m.f is:

It is to be signaled that, in coming EF study the last mentioned values of $T_{e m}$ and $E_{c}$ will be used to verify the calculated geometrical parameters of the obtained concept.

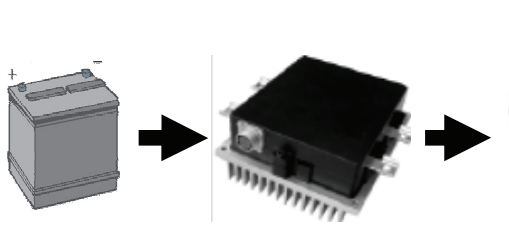

(a) (b)

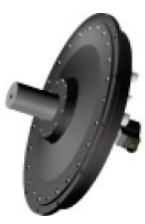

(c)

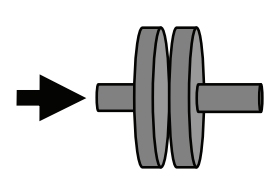

(d)

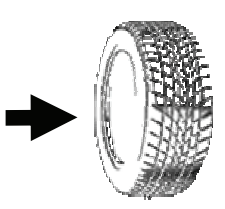

(e)

Figure 2. Integration of axial-flux motor in automotive traction chain. Legend: (a): a battery providing the input direct voltage of the inverter; (b): a conventional six-switch three-phase inverter insuring the generation of the three-phase voltage supplying the motor armature; (c): a permanent-magnet axial-flux motor with sinusoidal back e.m.f used for the vehicle driving; (d): a reducing system insuring the transmission of the motor mechanical energy to the vehicle wheels; (e): vehicle wheel 
A conventional six-switch three-phase inverter is used to supply the motor armature. In order to recuperate energy during the deceleration phases, the inverter has reversible structure.

In what follows, we are involved in an analytic calculation of the input direct voltage of the inverter $U_{\mathrm{dc}}$, and the maximum current intensity $\mathrm{I}_{\mathrm{ph}}$ feeding the motor phases.

\subsection{Design Criteria of Electrical Parameters for a Trapezoidal Wave Form Motor}

To supply this motor, currents in $120^{\circ}$ electric crenels shape are considered. The motor power supply appears as a succession of $60^{\circ}$ electric sequences during which two phases are simultaneously crossed by two opposite constant currents as shown in Figure 4.

Analysing Figure 4, one can notice that: 1): the motor back e.m.f is trapezoidal and 2): the resulting torque is as a simple juxtaposition of the three phase's constant torques. However, in order to limit the torque ripple, it is required to guarantee the right duration for each operation sequence and also an excellent form of the back e.m.f [8].

At the considered operation point, the electromagnetic torque of the motor is related to the phase current intensity as follows [9]:

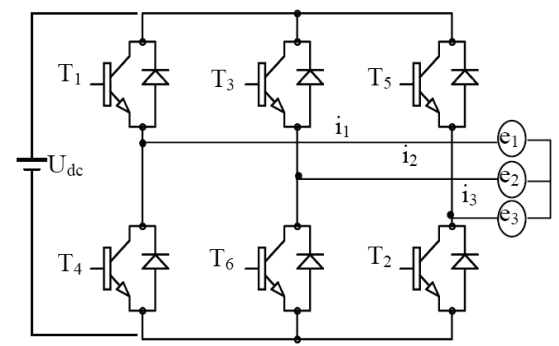

Figure 3. Six-switch three-phase inverter

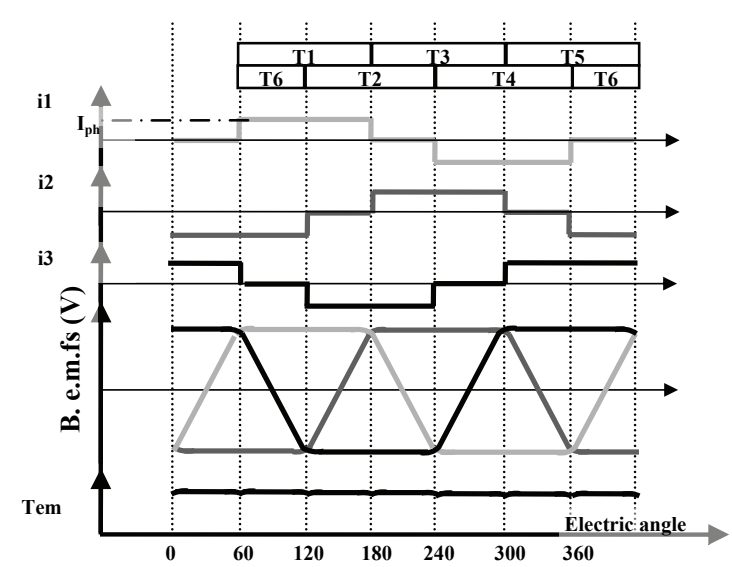

Figure 4. Power supplying of a trapezoidal wave form motor. Legend: T1, T2, T3, T4, T5 and T6: inverter switches; i1, i2, i3: phases currents; motor back e.m.fs; Tem: electromagnetic torque

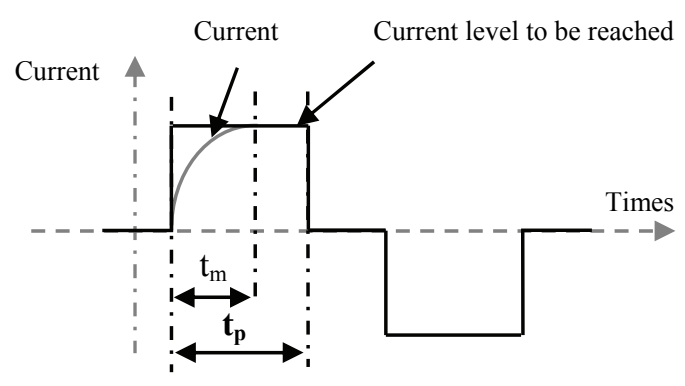

Figure 5. Shape of the phase current of the motor

At the considered operation point, the electromagnetic torque of the motor is related to the phase current intensity as follows [9]:

$$
T_{e m}=2 E_{C} I_{p h} / \Omega_{\max }=k_{e_{-} t r a} I_{p h}
$$

with $k_{e_{-} \text {tra }}=2 E_{C} / \Omega_{\max }=N_{s p h}\left(D_{e x t}^{2}-D_{\text {int }}^{2}\right) B_{e} / 2$ is the electric constant of the motor.

Consequently, the phase current intensity is:

$$
I_{p h}=T_{\text {ems }} / K_{e_{-} \text {tra }}
$$

Figure 5 illustrates the crenel shape of the current feeding motor phases.

The current wave form shows two important parameters [10]:

- The current maintaining time $\mathrm{t}_{\mathrm{p}}$ :

$$
t_{p}=(1 / 3)\left(2 \pi / p \Omega_{\max }\right)
$$

where $\Omega_{\max }$ is the maximum angular velocity of the motor.

- The current rising time $\mathrm{t}_{\mathrm{m}}$ :

$$
t_{m}=-(L / R) \ln \left(1-\left(2 R I_{p h} /\left(U_{d c}-K_{e_{-} t r a} \Omega_{\max }\right)\right)\right)
$$

with $\mathrm{R}$ and $\mathrm{L}$ are the phase resistance and the phase inductance, respectively.

The torque ripple factor $r$, is defined as [10]:

$$
r=t_{m} / t_{p}
$$

For a fixed value of the ripple factor, the input direct voltage $U_{\mathrm{dc}}$ can be obtained as follows:

$$
U_{d c}=\left(2 R I_{p h} /\left(1-\exp \left(-((2 \pi r) / 3) /\left(p \Omega_{\max } L / R\right)\right)\right)\right)+k_{e_{-} t r a} \Omega_{\max }
$$

\subsection{Design Criteria of Electrical Parameters for a Sinusoidal Wave Form Motor}

The output voltages of the inverter applied to the armature of the sinusoidal back e.m.f configuration of the permanent-magnet axial-flux motor are illustrated in Figure 6.

The fundamental of the back e.m.f of the first phase is 


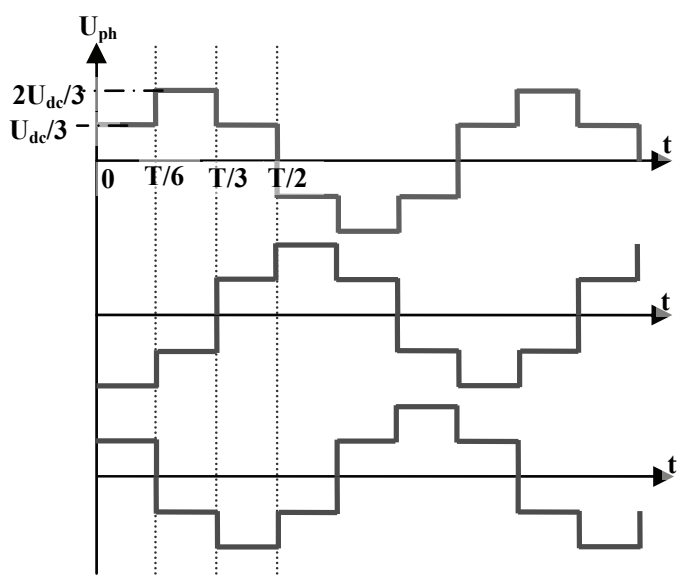

Figure 6. Phases voltages shapes

noted $\mathrm{U}_{\mathrm{ph} 11}$. It is expressed as the following [11]:

$$
U_{p h 11}(t)=\left(2 U_{d c} / \pi\right) \sin ((2 \pi / T) t+\phi)
$$

To guarantee operation regime under maximum torque, the motor piloting angle between the back e.m.f $\mathrm{E}_{\mathrm{C}}$ and the phase current $I_{p h}$ is fixed equal to zero in the control system. At the maximum speed, the maximum value of the fundamental can be simply obtained from the Fresnel diagram as:

$$
U_{p h 11}=\sqrt{\left(R I_{p h}+E_{C}\right)^{2}+\left(L \omega_{\max } I_{p h}\right)^{2}}
$$

where $\omega_{\max }$ is the maximum pulsation of motor voltage.

The input direct voltage $\mathrm{U}_{\mathrm{dc}}$ can so be calculated using the following expression:

$$
U_{d c}=(\pi / 2) \sqrt{\left(R I_{p h}+E_{C}\right)^{2}+\left(L \omega_{\max } I_{p h}\right)^{2}}
$$

At the considered operation point, the electromagnetic torque developed by the considered configuration of the motor is related to the phase current intensity as follows [9]:

$$
T_{e m}=(3 / 2)\left(E_{C} I_{p h} / \Omega_{\max }\right)=k_{e_{-} \sin } I_{p h}
$$

with $k_{e_{-} \sin }=3 E / 2 \Omega=3 N_{s p h}\left(D_{e x t}^{2}-D_{\text {int }}^{2}\right) B_{e} / 8$ is the electric constant of the motor.

Consequently, the phase current intensity is:

$$
I_{p h}=T_{e m s} / K_{e_{-} \sin }
$$

Furthermore and for both configurations of the motor: the permanent-magnet axial-flux motor with trapezoidal back e.m.f wave form and the permanent-magnet axial-flux motor with sinusoidal back e.m.f wave form, the armature parameters $\mathrm{R}$ and $\mathrm{L}$ are expressed as the following [12]:

- Phase resistance:

$$
R_{p h}=\rho\left(T_{b}\right) N_{t c} \delta L_{s p} / 6 I_{p h}
$$

with $\rho\left(T_{b}\right)$ is copper resistivity at the temperature $\mathrm{Tb}$, $\mathrm{N}_{\mathrm{tc}}$ is the total number of conductors, $\delta$ is the current density and $\mathrm{L}_{\mathrm{sp}}$ is the mean length of one turn.

- Phase inductance:

$$
L_{p h}=L_{e p}+L_{f p}
$$

with $L_{e p}$ is the air-gap inductance and $L_{f p}$ is the phase leakage inductance through one slot.

\subsection{Geometrical Parameters of the Motor}

The considered permanent-magnet axial-flux motor is composed of only one module containing two parts: one stator and one rotor, as illustrated in Figure 1(a).

The stator yoke is laminated and made up of iron-silicium, Figure 1(a). It contains 12 identical slots where the three phase winding is inserted. Totally, 6 coils are used and each phase is obtained by putting in series two appropriate coils, as shown in Figure 8. The stator teeth are of two kinds: 1) 6 large teeth called principal teeth, around which coils are winded, and 2) 6 small teeth located in between adjacent principal teeth, called inserted teeth. The width of the inserted tooth is variable depending on wished back e.m.f form.

The rotor is an iron massive disc where eight samarium-cobalt permanent magnets, with a remanent polarization of 1.175T, are mounted on its surface and four pole pairs are so obtained as shown in Figure 7(a) and (b).

Figure 9 shows the geometrical parameters necessary to define the structures of both configurations of the surface-mounted axial-flux permanent-magnet motor. Before calculating these geometrical parameters, specific coefficients have to be defined:

- $L_{p}=\pi / p$ : pitch in between poles.

- $\beta=L_{a} / L_{P}$ : rotor occupancy rate by permanent magnets. This coefficient is equal to 1 when the mounted permanent magnets cover the whole surface of the rotor, and is equal to 0.5 when permanent magnet surface is equal to the air one in rotor.

- $R_{\text {ldla }}=A_{p t m} / L_{a}$ : report between angular width of a principal tooth $\mathrm{A}_{\text {ptm }}$ by the angular width of a magnet $\mathrm{L}_{\mathrm{a}}$, Figure 7.

- $R_{n d n p}=N_{t e} / p$ : report of the teeth number $\left(\mathrm{N}_{\mathrm{te}}\right)$ by the number of pole pairs.

- $R_{\text {did }}=A_{i t m} / A_{p t m}$ : report between the angular width of an inserted tooth $\mathrm{A}_{\mathrm{itm}}$ by the angular width of a principal tooth $\mathrm{A}_{\mathrm{ptm}}$, Figure 7.

In coming finite elements study, the last defined coefficients are taken same as ones used in [9] and [10]. These coefficients are resumed in Table 2 (Appendix). In the mentioned works, $[9,10]$, it has been demonstrated that the considered values guarantee the best wave forms of gene- 

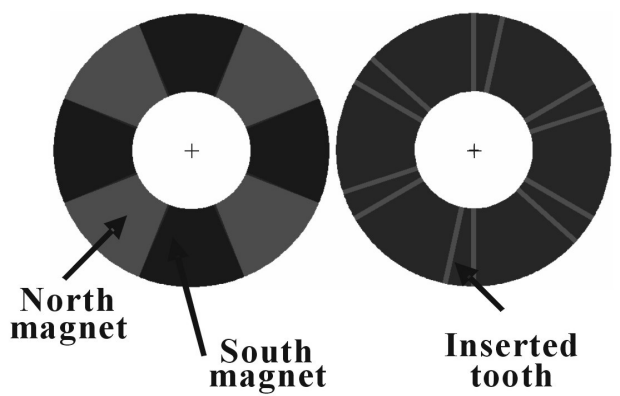

(a) Trapezoidal back e.m.f configuration

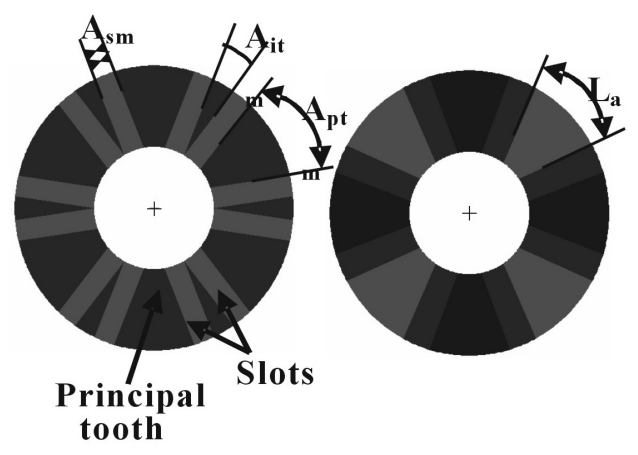

(b) Sinusoidal back e.m.f configuration

Figure 7. Structures of both configurations of the permanent-magnet axial-flux motor

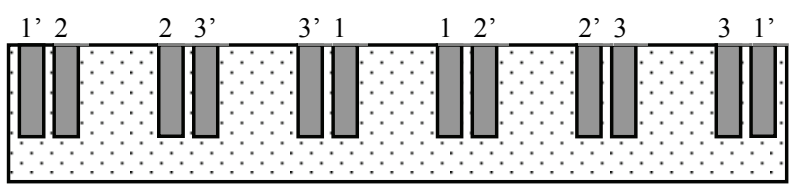

Figure 8. Cylindrical cut plan of the stator of the axial-flux motor

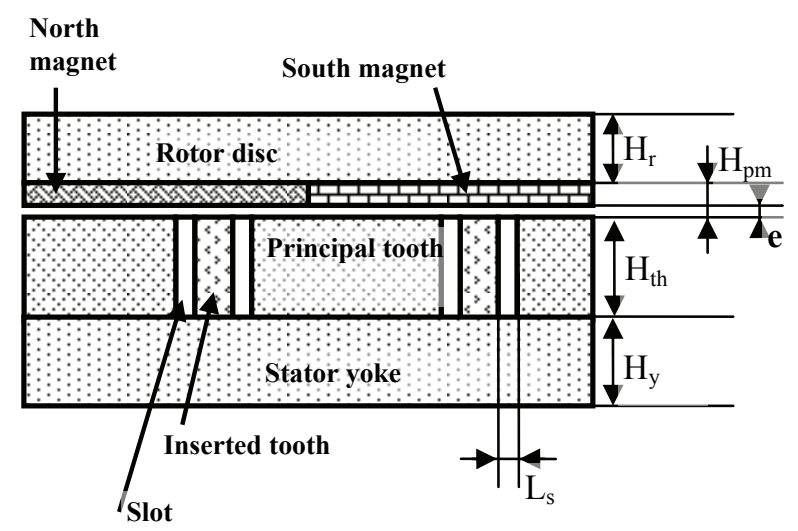

Figure 9. Geometrical parameters of the permanent-magnet axial-flux motor. Legend: Hr: rotor disc thickness; Hpm: permanent magnet height; Hth: slot height; Hy: stator yoke thickness; e: air-gap thickness; Ls: slot width rated fluxes and discard leakage fluxes between permanent magnets, for trapezoidal and sinusoidal motors.

Referring to [12], the motor geometrical parameters are calculated by integrating the mentioned coefficient in trigonometric formulas. The obtained geometrical parameters for both motor configurations are recapitulated in Table 2 (Appendix).

\section{Finite Elements Study}

In axial-flux motor, the magnetic phenomena are symmetrical according to the motor radial direction. Thus, the finite elements study of the two motor configurations can be simplified from 3D to 2D finite elements study which is simpler and more speed from the point of view of calculation time. The used software is MAXWELL 2D [13].

Figure 10 illustrates the finite elements study domain of the trapezoidal configuration of the axial-flux motor.

In order to validate the analytical calculated parameters, this study is intended to the computation of the generated fluxes in the motor air-gap which yields the back e.m.fs and the developed torque at load operation point. In the first step, the geometrical parameters analytically calculated in Subsection 2.3 are used to define the geometry used in the finite elements program. Then, in a second step and for different values of the rotor position, two different finite elements calculations are processed:

- An investigation of the effect of only the permanent magnets: the machine is working as a generator at no-load operation regime. The fluxes wave forms due to the permanent magnets effect are so carried out. Consequently, motor back e.m.fs wave forms and amplitudes are deduced which characterise the electric/mechanic power transfer.

- A computation under load operation point: the current feeding the motor armature is in phase with the back e.m.f obtained through the previous study. The so generated flux is used to find out the machine torque.

Figure 11 shows the flux lines through the magnetic circuit of the sinusoidal wave form configuration of the axial-flux motor due to the effect of only the permanent magnets and Figure 12 shows the flux lines through the magnetic circuit of the sinusoidal wave form configuration of the axial-flux motor under load operation.

Analyzing these figures, one can notice that leakage fluxes between permanent magnets do not exist and all generated fluxes are useful.

\subsection{Finite Elements Study at Generation Mode}

For both configurations of the axial-flux motor, the considered operation point corresponds to the maximum speed of the vehicle $(80 \mathrm{~km} / \mathrm{h})$ which means an angular velocity equal to $341.88 \mathrm{rad} / \mathrm{s}$. For trapezoidal configura- 


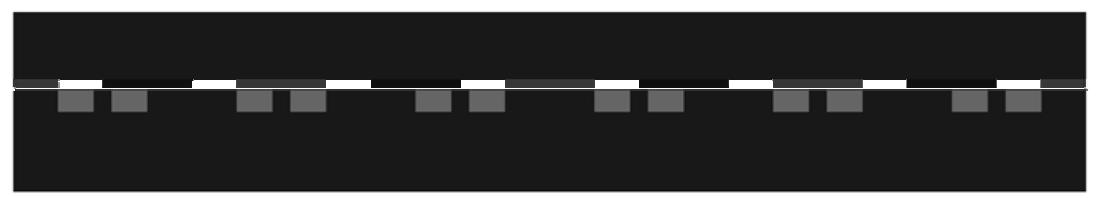

Figure 10. Cylindrical cut plan of the trapezoidal wave form motor

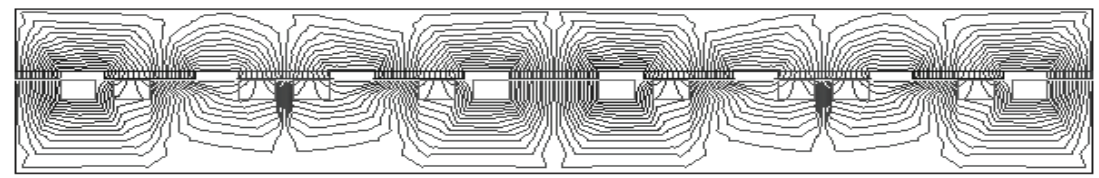

Figure 11. Flux lines through the magnetic circuit of the sinusoidal wave form configuration of the axial-flux motor due to the effect of only the permanent magnets

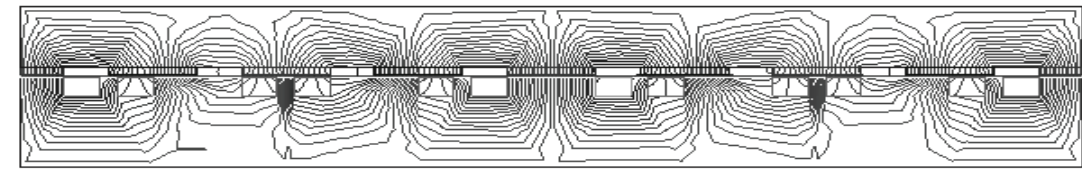

Figure 12. Flux lines through the magnetic circuit of the sinusoidal wave form configuration of the axial-flux motor under load operation

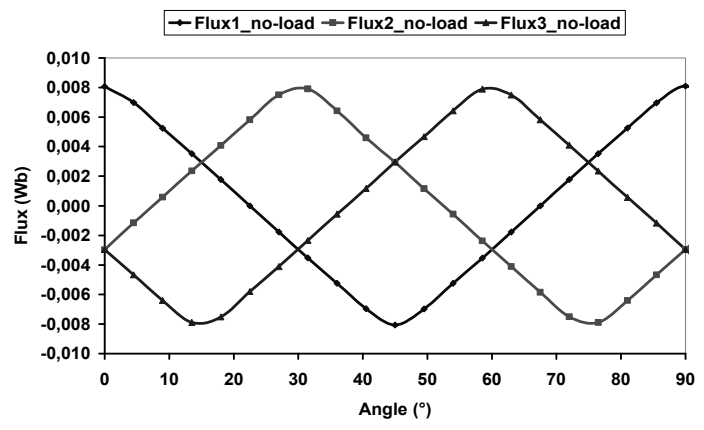

(a) Trapeze case

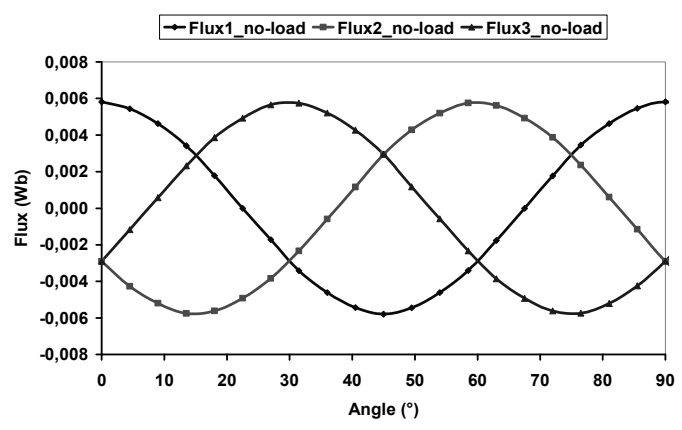

(b) Sine case

Figure 13. Fluxes generated in the air-gap of the machine for a generation regime at no-load operation and for a vehicle speed of $80 \mathrm{~km} / \mathrm{h}$

tion and sinusoidal one, the wave form of generated fluxes in the air-gap are illustrated respectively in Figure 13 (a) and (b) where rotor position is varied from $0^{\circ}$ to $90^{\circ}$.
For each motor phase, the back e.m.f can be obtained considering a perfect magnetic circuit and using the following expression:

$$
e_{C}(t)=-N_{s p h} d \varphi_{p h} / d t=-N_{s p h}(d \theta / d t)\left(d \varphi_{p h} / d \theta\right)=-N_{s p h} \omega d \varphi_{p h} / d \theta
$$

with $\theta$ is the rotor position and $\varphi_{p h}$ is the flux of the considered phase.

The differential $d \varphi_{p h} / d \theta$ can be obtained by a linearization between two consecutive positions and the back e.m.f is so expressed as:

$$
e_{C}\left(\theta_{1}\right)=-N_{s p h} \omega\left(\varphi_{p h}\left(\theta_{1}\right)-\varphi_{p h}\left(\theta_{2}\right)\right) /\left(\theta_{1}-\theta_{2}\right)
$$

Figure 14 shows the wave form of the obtained back e.m.fs for both axial-flux motor configurations.

Analyzing those figures one can remark that in the case of the trapezoidal configuration of the motor the gener- ated back e.m.fs are perfectly trapezoidal and in the case of the sinusoidal motor configuration the generated back e.m.fs are also perfectly sinusoidal.

\subsection{Finite Elements Study under Load Operation}

In this section, the motor is considered under load operation regime. The motor armature is supplied by three currents in phase with the back e.m.fs obtained at the no-load operation of the generation regime. As illustrated in Figure 15(a) and (b), crenel shape currents with a maximum intensity $\mathrm{I}_{\mathrm{ph} \_ \text {trapeze }}=50.154 \mathrm{~A}$ are used for the trapezoidal configuration, and sinusoidal shape currents with a 


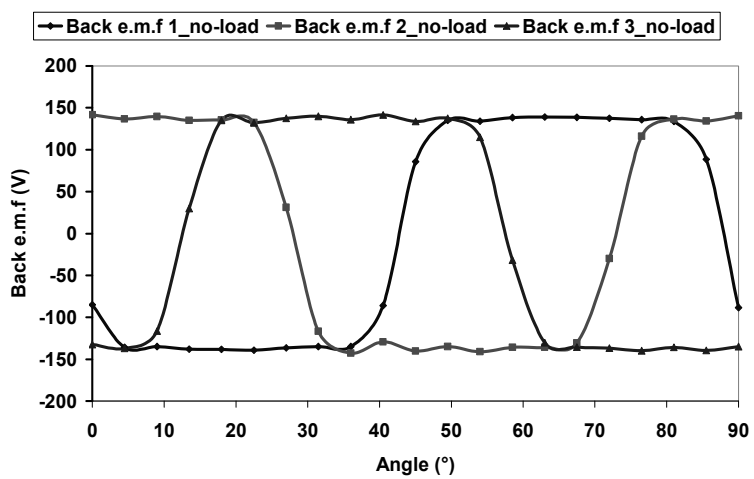

(a) Trapeze case

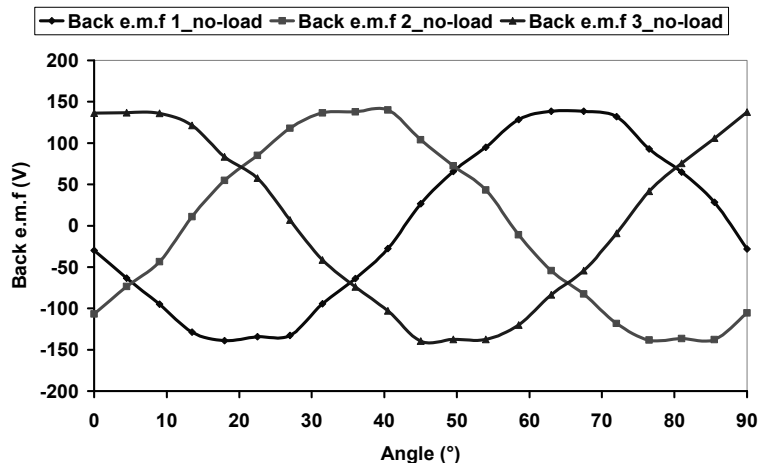

(b) Sine case

Figure 14. Wave form of the generated back e.m.f for a generation regime at no-load operation and for a vehicle speed of $80 \mathrm{~km} / \mathrm{h}$

maximum intensity $\mathrm{I}_{\mathrm{ph} \_ \text {sine }}=66.872 \mathrm{~A}$ are used for the sinusoidal configuration.

Figure 15(c) and Figure 15(d) illustrate the wave form of obtained fluxes in the motor air-gap for the maximum vehicle speed $(80 \mathrm{~km} / \mathrm{h})$, and different rotor positions varying from $0^{\circ}$ to $90^{\circ}$, respectively for trapezoidal and sinusoidal motors. Analysing these figures, one can notice the appearance of flux distortion at the load operation regime in respect with the no-load operation one. This distortion is essentially due to the magnetic armature reaction.

Considering Equation (16) and for a perfect magnet circuit, the back e.m.f of the motor can be calculated and illustrated as shown in Figure 15(e) and (f) for trapezoidal and sinusoidal configurations, respectively. Referring to the aforementioned figures, one can remark the following: 1): for both configurations the analytical maximum value of the back e.m.f $E_{c}=138.462 \mathrm{~V}$ is reached, $2)$ : the sinusoidal configuration generates a sinusoidal back e.m.f without peaks which yields a torque wave form with no peaks, Figure 15(h). However, the trapezoidal configuration generates a trapezoidal distorted back e.m.f containing several peaks giving a torque wave form with several peaks too, Figure $15(\mathrm{~g})$.

Referring to Figure $15(\mathrm{~g})$ and $(\mathrm{h})$, both motors are able to develop the requested torque. The ripple figuring in the torques wave forms is due essentially to the motors cogged structures which cause the appearance of a cogging torque. Considering the obtained torques wave forms, vibration problems due to the torque ripple are sharper in the case of trapezoidal motor than in the case of the sinusoidal one. For that, in coming study, only the features of the permanent-magnet axial-flux sinusoidal motor are investigated.

\section{Traction Chain Modelling}

The present section is devoted to the modelling of an axial-flux motor with sinusoidal back e.m.f wave form associated to a six-switch three-phase inverter for traction application. The whole traction chain is modelled in order to investigate the motor behaviour vis-à-vis of a desired speed sequence and of the circulation mission of the National Institute of Research on Transports and their Security (INRETS).

Figure 16 shows the block diagram of the adopted control vector strategy of the motor implemented under MATLAB/SIMULINK environment.

The synchronous permanent magnet machine can be described in the d-q referential as follows [14]:

$$
\left\{\begin{array}{l}
V_{d}=R i_{d}+L_{d}\left(d i_{d} / d t\right)-\omega_{e} L_{q} i_{q} \\
V_{q}=R i_{q}+L_{q}\left(d i_{q} / d t\right)-\omega_{e} L_{d} i_{d}+K_{e} \omega_{m}
\end{array}\right.
$$

with $\omega_{\mathrm{e}}$ is the electric pulsation, $\mathrm{L}_{\mathrm{d}}$ and $\mathrm{L}_{\mathrm{q}}$ are respectively direct in squaring inductances.

The direct and in squaring components of the current can be deduced using:

$$
\left\{\begin{array}{l}
I_{d}=\left(V_{d}+\omega_{e} L_{q} i_{q}\right) / L_{d} S+R \\
I_{q}=\left(V_{q}+\omega_{e} L_{d} i_{d}-K_{e} \omega_{m}\right) / L_{q} S+R
\end{array}\right.
$$

with $\mathrm{S}$ is Laplace operator.

The developed electromagnetic torque is so expressed [15]:

$$
T_{e m}=(3 / 2) K_{e} I_{q}+(1 / 2) p\left(L_{d}-L_{q}\right) I_{d} I_{q}
$$

Considering the fundamental dynamic law describing the vehicle motion, the torque needed on wheels is:

$$
T_{w}=T_{b r}+T_{\text {aero }}+T_{g}+\sigma M_{v} R_{w} d V / d t=T_{r}+\sigma M_{v} R_{w} d V / d t
$$

with $T_{b r}$ is the torque due to bearing resistance force, $T_{\text {aero }}$ is the torque due to aerodynamic load, $T_{g}$ is the torque due to gravity forces, $\sigma$ a coefficient related to the inertia 


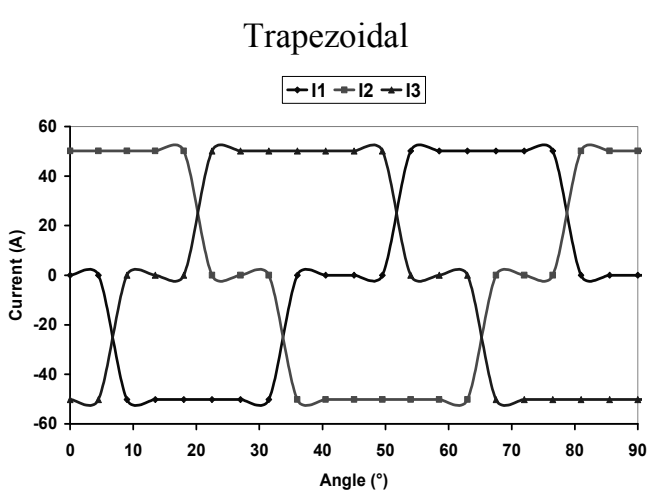

(a) Three phase current

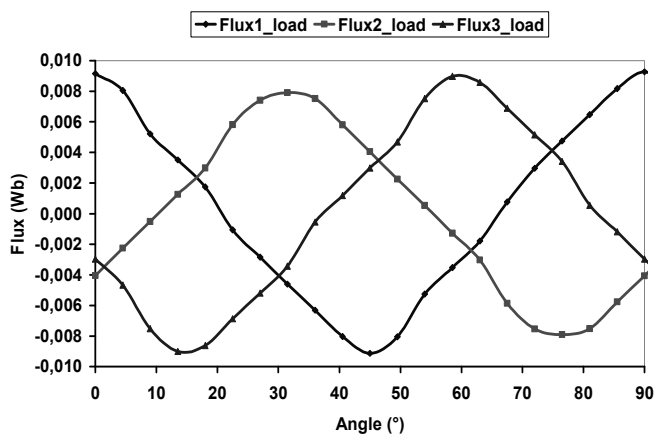

(c) Air-gap fluxes

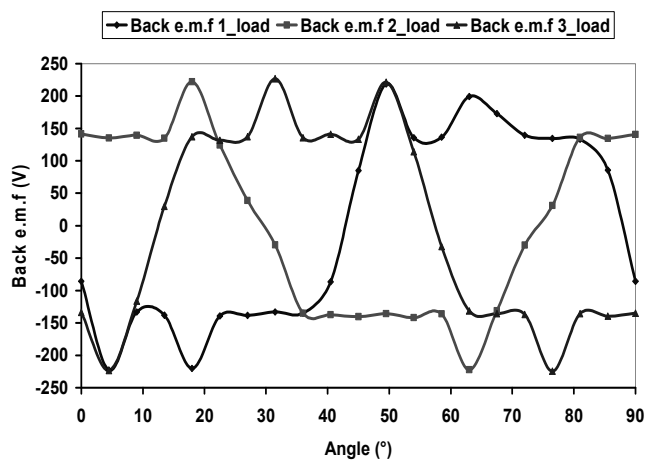

(e) Back e.m.fs

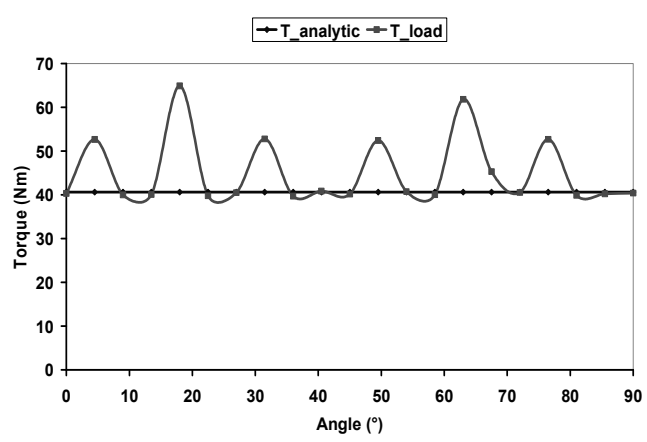

(g) Electromagnetic torque

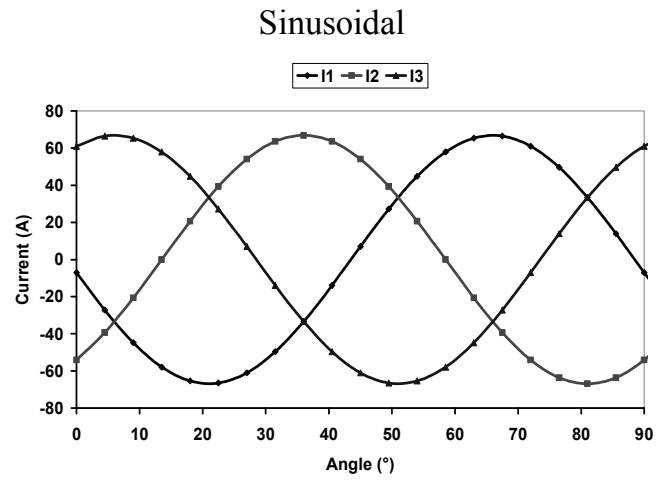

(b) Three phase current

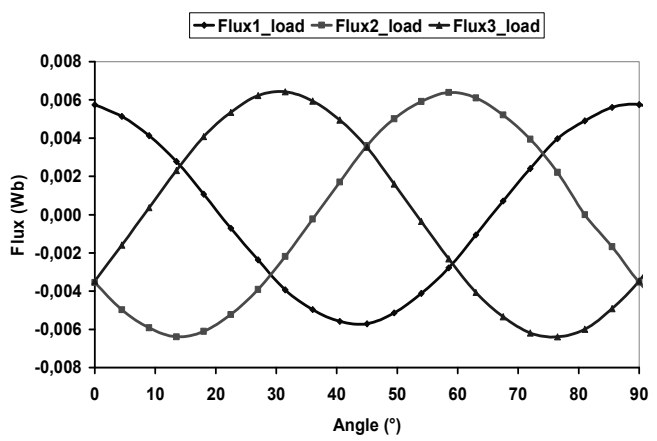

(d) Air-gap fluxes

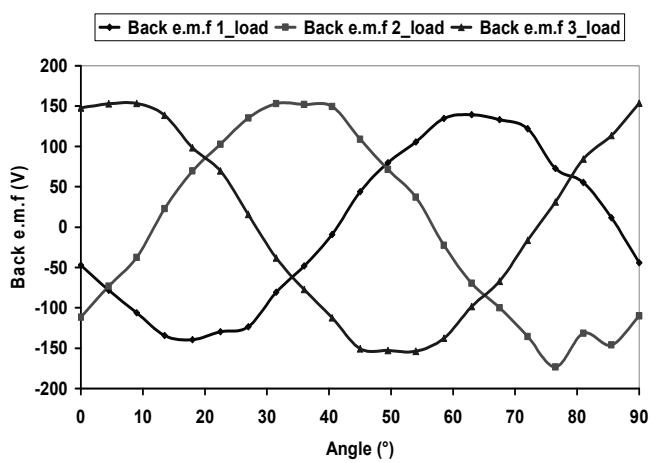

(f) Back e.m.fs

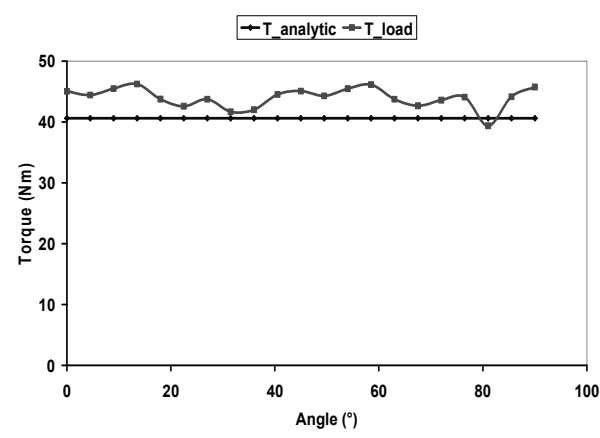

(h) Electromagnetic torque

Figure 15. Load operation of trapezoidal and sinusoidal motor configurations 


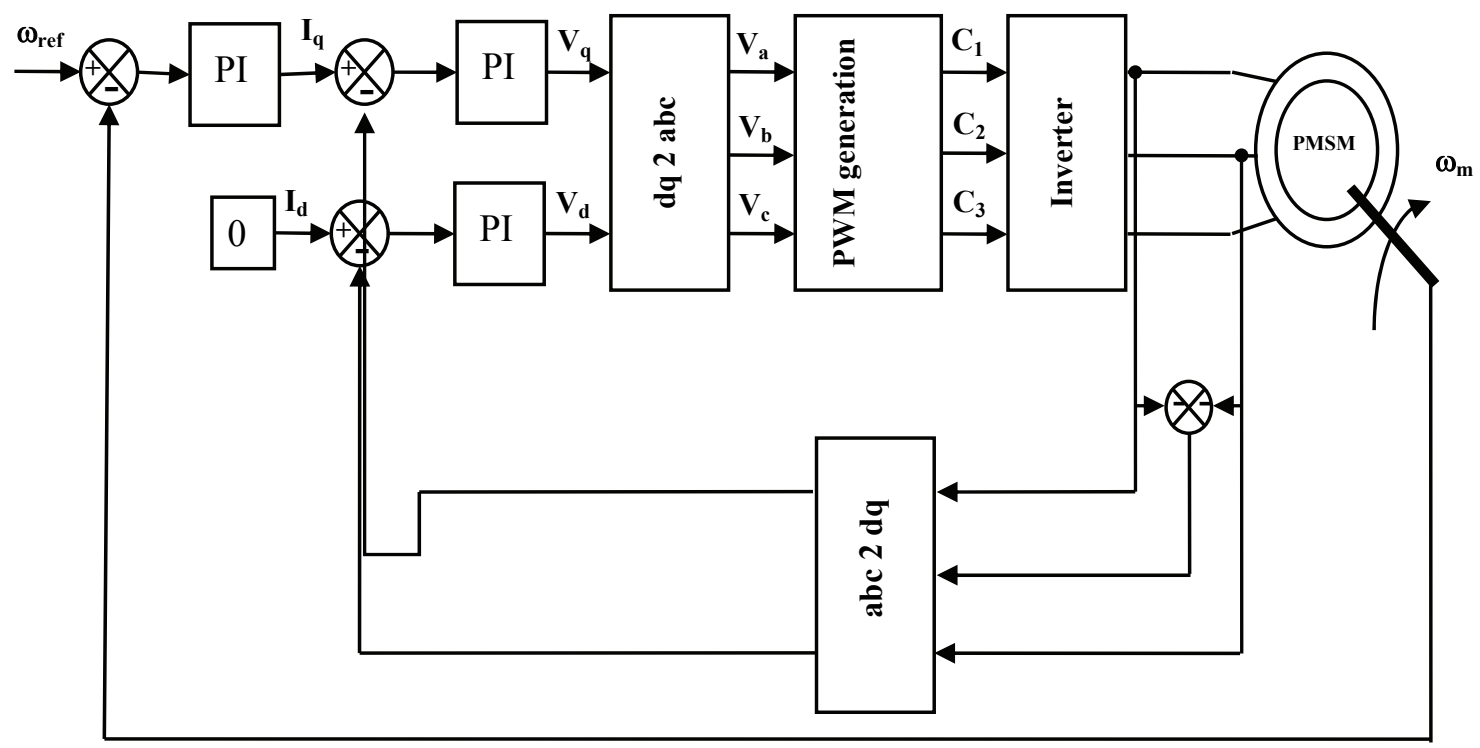

Figure 16. Block diagram of the vector control strategy of the axial-flux motor

of turning parts (wheels, driving shaft and gearing system) and $T_{r}$ is the resistive torque.

The control strategy block diagram, shown in Figure 16 , presents two regulation loops: the first loop is used for speed regulation and the second one for current regulation. The control vector strategy operates with only the in squaring component of the current. For that the direct current is cancelled and its reference value is fixed to zero. Consequently, referring to Equation (20), the developed electromagnetic torque is expressed as:

$$
T_{e m}=(3 / 2) K_{e} I_{q}
$$

The Inverter switches are driven using PWM control signals and the three voltages provided to supply the motor armature are:

$$
\left\{\begin{array}{l}
U_{p h 1}=\left(U_{d c} / 3\right)\left(2 C_{1}-C_{2}-C_{3}\right) \\
U_{p h 2}=\left(U_{d c} / 3\right)\left(2 C_{2}-C_{1}-C_{3}\right) \\
U_{p h 3}=\left(U_{d c} / 3\right)\left(2 C_{3}-C_{2}-C_{1}\right)
\end{array}\right.
$$

with $\mathrm{U}_{\mathrm{ph} 1}, \mathrm{U}_{\mathrm{ph} 2}, \mathrm{U}_{\mathrm{ph} 3}$ are the three phase voltage provided by the inverter, and $\mathrm{C}_{1}, \mathrm{C}_{2}, \mathrm{C}_{3}$ are the command constants for the inverter high transistors $T_{1}, T_{3}$ and $T_{5}$, respectively.

The constants $\mathrm{C}_{1}, \mathrm{C}_{2}$ and $\mathrm{C}_{3}$ are generated using a PWM generation block, Figure 17, based on the comparison between a triangular signal which frequency is equal to the desired commutation frequency of the inverter switches and a sinusoidal one which pulsation gives the desired motor speed. A transistor switched on corresponds to $\mathrm{C}=1$, and a transistor switched off corresponds to $\mathrm{C}=0$.
At vehicle maximum speed $(80 \mathrm{~km})$ and for the geometrical parameters analytically calculated and validated by the finite elements study, the direct voltage applied to the inverter $U_{d c}$, the motor resistance $R$, the direct inductance of the motor $L_{d}$, the in squaring inductance of the motor $\mathrm{L}_{\mathrm{q}}$ and the electric constant of the motor $\mathrm{K}_{\mathrm{e}}$ are analytically determined, Table 3 (Appendix). For the obtained values and for a switching frequency $\mathrm{f}_{\mathrm{c}}=3.3 \mathrm{kHz}$, the inverter provides three chopped and equilibrated voltages to supply motor armature, Figure 18.

\subsection{Simulation Results}

\subsubsection{Speed Sequence}

The desired speed sequence, Figure 19, requires three speed levels. Considering the parameters given by Table 3,

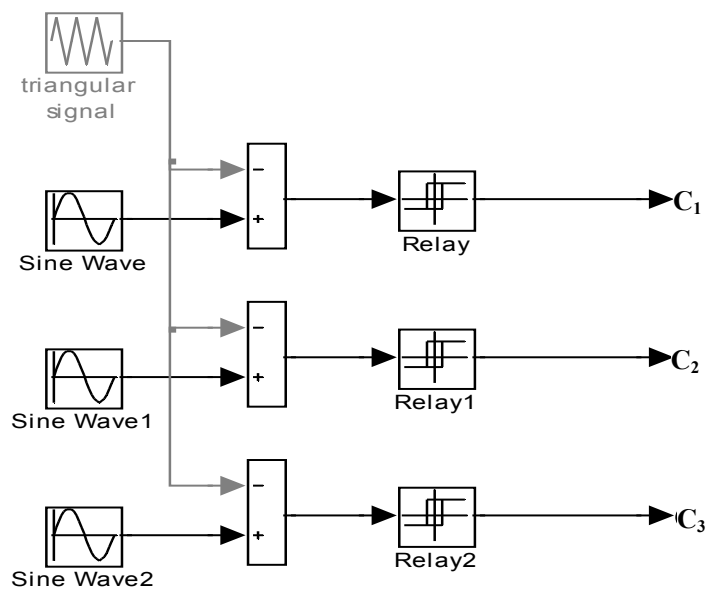

Figure 17. Generation of the inverter command constants 


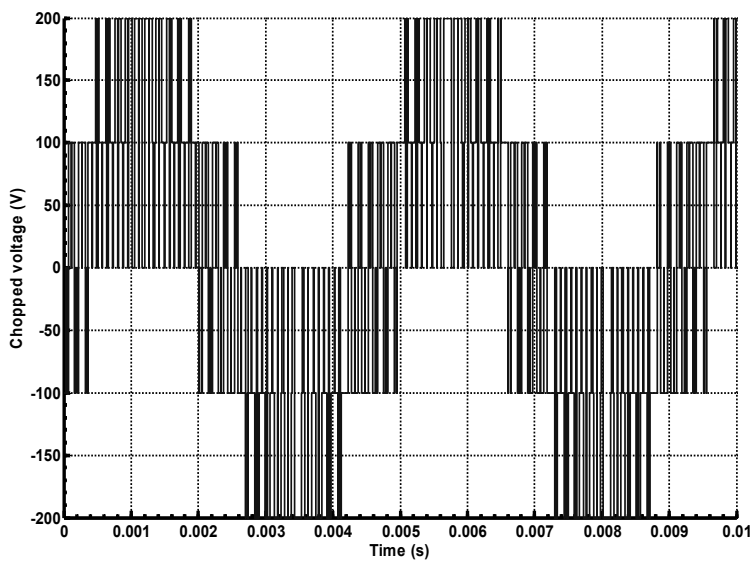

Figure 18. Motor phase chopped voltage provided at the output of the inverter

the motor speed carried out using the traction elaborated traction chain model is illustrated in Figure 19. Analyzing this figure, one can notice that the vehicle speed reaches the wanted value in a relatively weak time.

\subsubsection{Circulation Mission}

To validate the use of a motor for traction application, the INRETS tests the behaviour of such motor using the speed instruction illustrated in Figure 20(a). Such speed instruction is called circulation mission. It consists of a normalised trial for vehicle motor tested for long distances and variable speed under hard constraints.

In the last section, the designed motor was able to fol- low a desired speed instruction. For the present study, let us consider the INRETS circulation mission and investigate the motor behaviour.

Figure 20(b) shows that the electric vehicle speed follows to the required circulation mission with a little delay as found in Subsection 5.1.1.

\section{Conclusions}

The present paper was devoted to the design of high power - low dimensions axial-flux permanent-magnet motor for electric vehicles. In a first step, the electrical and the geometrical parameters of the motor integrated in the whole traction chain was analytically calculated considering the vehicle specifications. Then in a second step, we have been interested in a finite elements study in order to validate and complete the analytical obtained results. It has been found, that the built analytical model provides accurate values of electrical and geometrical motor parameters. Furthermore, a comparison between the electromagnetic torque obtained by the trapezoidal configuration and one developed by the sinusoidal configuration was made using the finite elements study. The high ripple noticed in the wave form of trapezoidal motor's torque leads to discard this configuration and emphasize the choice of sinusoidal configuration for traction applications. Finally, the designed sinusoidal motor behaviour was investigated considering firstly a desired

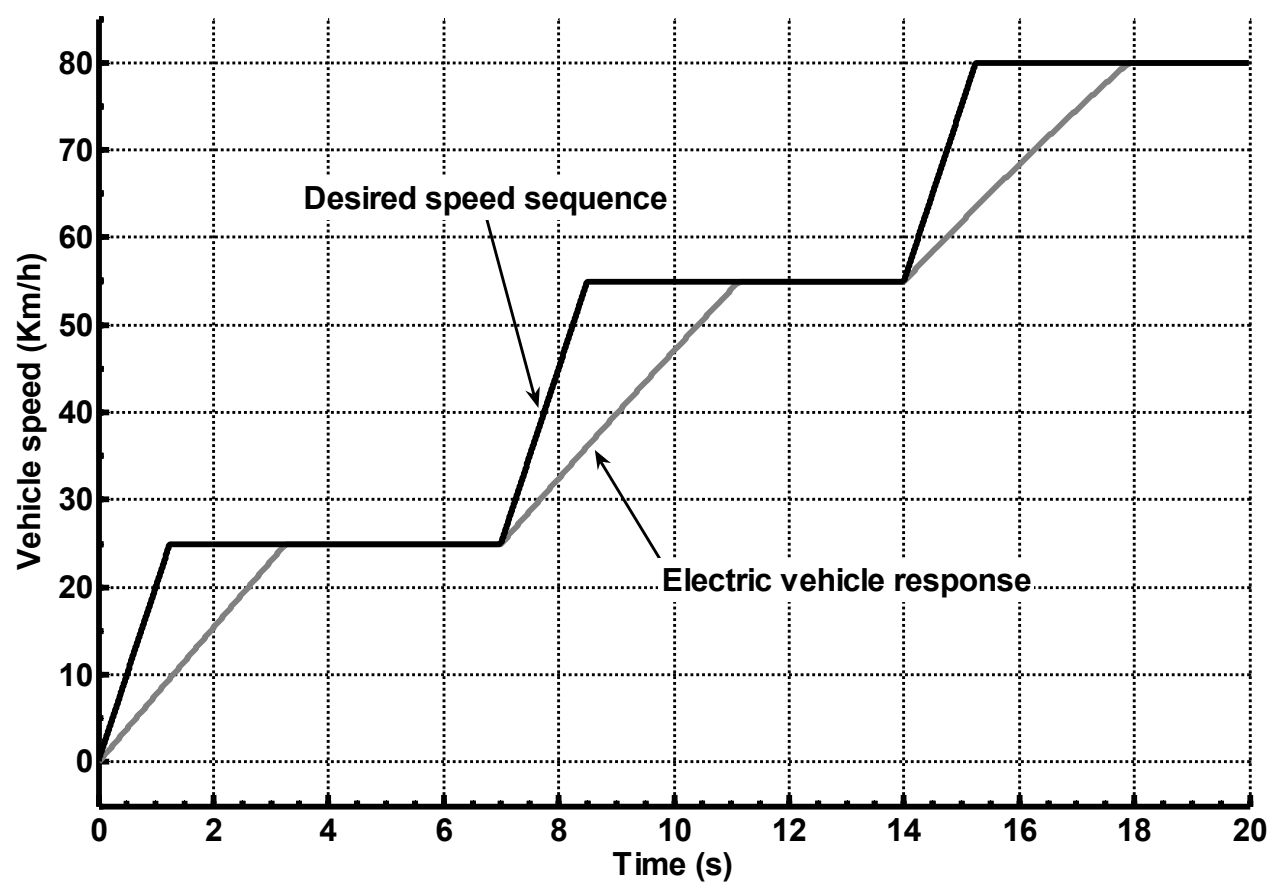

Figure 19. Desired speed sequence and motor speed carried out using the developed traction chain model 


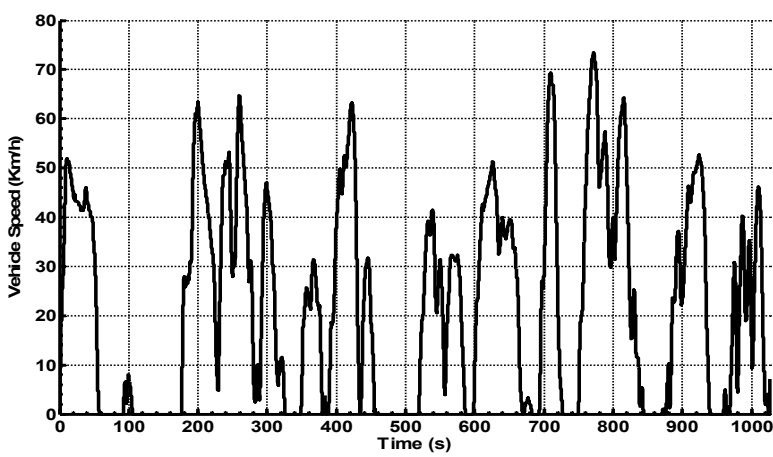

(a) INRETS circulation mission

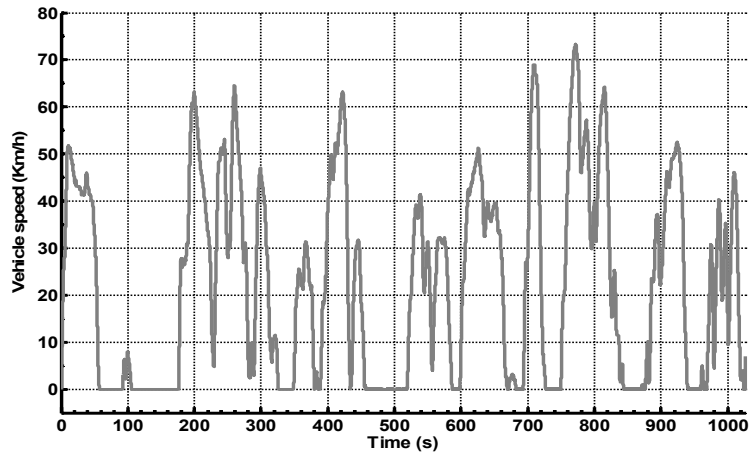

(b) Electric vehicle response

Figure 20. INRETS circulation mission and electric vehicle response

speed instruction and next the INRETS circulation mission. For that, we have been involved in the modelling and implementation under matlab/simulink environment of such motor associated to six-switch three-phase inverter and integrated in the whole traction chain. For both tests, the motor was able to follow and to provide the requested features which make the sinusoidal axial-flux permanent-magnet motors serious competitors of conventional radial-flux permanent-magnet motors for automotive traction applications.

\section{Appendix}

Table 1. Motor specification

\begin{tabular}{|c|c|c|c|}
\hline Parameter & symbol & value & unit \\
\hline Vehicle mass & $\mathrm{M}_{\mathrm{v}}$ & 800 & $\mathrm{~kg}$ \\
\hline Wheel ray & $\mathrm{R}_{\mathrm{w}}$ & 0.26 & $\mathrm{~m}$ \\
\hline Basic velocity & $\mathrm{V}_{\mathrm{b}}$ & 30 & $\mathrm{~km} / \mathrm{h}$ \\
\hline Maximum speed of the vehicle & $\mathrm{V}_{\max }$ & 80 & $\mathrm{~km} / \mathrm{h}$ \\
\hline Pole pair number & $\mathrm{p}$ & 4 & \\
\hline Stating time & $t_{d}$ & 4 & $\mathrm{~s}$ \\
\hline Coefficient related to the inertia if the turning parts & $\sigma$ & 1 & \\
\hline Switched frequency & $f_{c}$ & 3.33 & $\mathrm{kHz}$ \\
\hline Reduction report & $r_{d}$ & 4 & \\
\hline Gravity & g & 9.81 & $\mathrm{~N} / \mathrm{kg}$ \\
\hline External diameter & $D_{\text {ext }}$ & 350 & $\mathrm{~mm}$ \\
\hline Internal diameter & $D_{\text {int }}$ & 150 & $\mathrm{~mm}$ \\
\hline
\end{tabular}

Table 2. Motor dimensioning

\begin{tabular}{|c|c|c|c|}
\hline Designation & Symbol & Trapeze & Sine \\
\hline Report of the teeth number by the number of pole pairs & $\mathrm{R}_{\text {ndnp }}$ & 1.5 & 1.5 \\
\hline Rotor occupancy rate by permanent magnets & $\beta$ & 1 & $2 / 3$ \\
\hline Report between angular width of a principal tooth by the angular width of a magnet & $\mathrm{R}_{\text {ldla }}$ & 1 & 1 \\
\hline Report between the angular widths of an inserted tooth by the angular width of a principal toot. & $\mathrm{R}_{\text {did }}$ & 0.2 & 0.2 \\
\hline Rotor disc thickness & $\mathrm{H}_{\mathrm{r}}$ & $83.357 \mathrm{~mm}$ & $55.611 \mathrm{~mm}$ \\
\hline Permanent magnets height & $\mathrm{H}_{\mathrm{pm}}$ & $6.873 \mathrm{~mm}$ & $6.873 \mathrm{~mm}$ \\
\hline Slots height & $\mathrm{H}_{\text {th }}$ & $69.671 \mathrm{~mm}$ & $17.214 \mathrm{~mm}$ \\
\hline Stator yoke thickness & $\mathrm{H}_{\mathrm{y}}$ & $98.176 \mathrm{~mm}$ & $65.498 \mathrm{~mm}$ \\
\hline Slots mean angular width & $\mathrm{A}_{\mathrm{sm}}$ & $3^{\circ}$ & $12^{\circ}$ \\
\hline Slots width & $\mathrm{L}_{\mathrm{s}}$ & $6.545 \mathrm{~mm}$ & $26.132 \mathrm{~mm}$ \\
\hline Magnet mean angular width & $\mathrm{L}_{\mathrm{a}}$ & $45^{\circ}$ & $30^{\circ}$ \\
\hline Principal tooth mean angular width & $\mathrm{A}_{\mathrm{ptm}}$ & $45^{\circ}$ & $30^{\circ}$ \\
\hline Inserted tooth mean angular width & $\mathrm{A}_{\mathrm{itm}}$ & $9^{\circ}$ & $6^{\circ}$ \\
\hline Air-gap thickness & $\mathrm{e}$ & $2 \mathrm{~mm}$ & $2 \mathrm{~mm}$ \\
\hline
\end{tabular}


Table 3. Electric parameters used for the simulation of the traction chain model

\begin{tabular}{|c|c|c|c|}
\hline Parameter & symbol & value & unit \\
\hline Direct voltage & $\mathrm{U}_{\mathrm{dc}}$ & 291 & $\mathrm{~V}$ \\
\hline Drag coefficient & $\mathrm{C}_{\mathrm{x}}$ & 0.55 & \\
\hline Coefficient to bearing pneumatic resistance & $f_{r}$ & 0.01 & \\
\hline Electric constant & $\mathrm{K}_{\mathrm{e}}$ & 0.3 & \\
\hline In squaring inductance & $\mathrm{L}_{\mathrm{q}}$ & 0.157 & $\mathrm{mH}$ \\
\hline
\end{tabular}

\section{REFERENCES}

[1] Y. Amara, "Contribution à la conception et à la commande des machines synchrones à double excitation, Application au véhicule hybride," Thèse de doctorat, université, PARIS VI, 2001.

[2] A. Parviainen, "Design of axial-flux permanent-magnet low-speed machines and performance comparison between radial-flux and axial-flux machines," thesis of doctorate, Lappeeranta University of Technology, Lappeeranta, Finland, 2005.

[3] A. Parviainen, M. Niemelä, J. Pyrhönen, J. Mantere, "Performance comparison between low-speed axial-flux and radial flux permanent-magnet machines including mechanical constraints," Electric Machines and Drives, IEEE International Conference, pp. 1695-1702, 2005.

[4] S. Tounsi, "Modélisation et optimisation de la motorisation et de l'autonomie d'un véhicule électrique," Thèse de doctorat en Génie Electrique, Ecole Nationale d'Ingénieurs de Sfax-Tunisie, 2006.

[5] B. Multon and J. Bonal, "Les entraînements électromagnétiques directs: Diversité, contraintes et solutions, La conversion électromécanique directe," - ENS Cachan SEE, 1999.

[6] P. Kurronen, "Torque vibration model of axial-flux surface-mounted permanent magnet synchronous machine," Dissertation, Lappeenranta University of Technology, Finland, 2003.

[7] B. Tounsi, "Etude comparative de groupes électrogènes embarqués à large gamme de vitesse variable associant machines à aimants permanents et conversion statique," Thèse de Doctorat, INP Toulouse, 2006.

[8] S. Tounsi, R. Neji, and F. Sellami, "Contribution à la conception d'un Actionneur à Aimants Permanents pour Véhicules Electriques en vue d'Optimiser l'Autonomie," Revue Internationale de Génie Electrique, RIGE, Vol. 9/6, pp. 693-718, Edition Lavoisier, 2006.

[9] C. Cavallaro, A. O. Di Tommaso, R. Miceli, A. Raciti, G. R. Galluzzo, and M. Trapanese, "Efficiency enhancement of permanent-magnet synchronous motor drives by online loss minimization approaches," IEEE Transactions on Industrial Electronics, Vol. 52, No. 4, pp. 1153-1160, 2005.

[10] R. Neji, S. Tounsi, and F. Sellami, "Contribution to the definition of a permanent magnet motor with reduced production cost for the electrical vehicle propulsion," European Transactions on Electrical Power, ETEP, Vol. 16, No. 4, pp. 437-460, 2006.

[11] R. Neji, S. Tounsi, and F. Sellami, "Optimization and design for a radial flux permanent magnet motor for electric vehicle," Journal of Electrical Systems, JES, Vol. 1, No. 4, 2005.

[12] N. Chaker, "Conception et commande d'un moteur à aimant permanent à flux axial pour véhicule électrique," Mémoire de Mastère en génie électrique, Ecole Nationale d'Ingénieurs de Sfax, Tunisie, 2006.

[13] MAXWELL® 2D (2002) Student Version; A 2D Magnetostatic Problem.

[14] F. Khatounian, S. Moreau, J. P. Louis, E. Monmasson, F. Louveau, and J. M. Alexandre, "Modeling and simulation of a hybrid dynamic system used in haptic interfaces," Electrimacs, Hammamet, Tunisie, 2005.

[15] G. Kayhan, A. A. Ahmed, and P. Halit, "Improving the performance of hysteresis direct torque control of IPMSM using active filter topology," $\mathrm{S}^{-}$adhan ${ }^{-} \mathrm{a}$, Vol. 31, Part 3, pp. 245-258, 2006. 